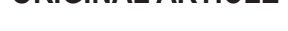

\section{Study on Thermal Insulation Measures for Construction of Reinforcement Sleeve Grouting Connection in Winter}

\author{
Fangzhen Zhu ${ }^{1}$, Wenbo $\mathrm{Li}^{1}$, Benguo Xing ${ }^{2}$, Lulu Zhang ${ }^{1}$ \\ ${ }^{1}$ Civil Engineering School Zhengzhou University Zhengzhou 450000 \\ ${ }^{2}$ China Construction Bureau Group No. 2 Construction Co., Ltd. Beijing 100000
}

Abstract: In this paper, the feasibility of winter construction of steel sleeve grouting connection is studied, and two technical schemes of thermal insulation measures for winter construction are provided. This paper mainly introduces the experimental research work of sleeve grouting by simulating winter construction, including test scheme, test operation flow, test equipment and test data collection and analysis. It is concluded that the thermal insulation measures of prefabricated wall panel covering electric heating blanket, XPS insulation board and sleeve outer wall winding electric companion heat preservation are feasible. Finally, according to the actual project case to verify the feasibility of thermal insulation measures, so that the project can progress smoothly, for similar projects in winter construction to provide reference and reference.

Keywords: Prefabricated Assembly Type; Sleeve Grouting; Winter Construction; Heat Preservation Measures

\section{Introduction}

At present, fabricated structure is a new direction of research and development in the field of architecture in China, and has attracted the attention of many scholars and enterprises. Steel sleeve grouting connection technology as the core technology of prefabricated buildings, has become the key to the smooth promotion of prefabricated buildings. Sleeve grouting connection consists of grouting sleeve, grouting material and connecting steel bars, so that the upper and lower steel bars can be effectively connected to work together.

The Technical Regulations for Grouting Connection of Steel Sleeves stipulate that it is not suitable for use below $5^{\circ} \mathrm{C}$ and ${ }^{[1]}$ is prohibited for use below $0{ }^{\circ} \mathrm{C}$. This has caused great limitations to the construction organization and time limit arrangement as well as the promotion of fabricated buildings. In response, Gu Haosheng et al. ${ }^{[2]}$ obtained that the curing temperature has a great influence on the early strength of grouting material by studying the influence of ambient temperature on the performance of reinforced sleeve grouting joint. In negative temperature environment, the hydration reaction of grouting material is not obvious, and the sleeve specimen does not have strength. Yang Guogang et $a l .{ }^{[3]}$ developed a sleeve grouting material for low-temperature early-strength steel bar connection, and obtained the temperature and ambient temperature pairs of different mixing water. Effect of sleeve grouting material on mechanical properties. However, due to the fact that China has not yet released the testing standards for low-temperature grouting materials, different low-temperature grouting materials are used in various projects.

It lacks necessary testing basis, and its use result is unpredictable. moreover, most of the low-temperature grouting materials sold on the market are suitable for above- $5{ }^{\circ} \mathrm{C}$. when the temperature is below $-5{ }^{\circ} \mathrm{C}$, thermal insulation measures $^{[4]}$ still need to be taken. in addition, the fluidity of low-temperature grouting materials is difficult to meet the operation requirements during construction in low-temperature environment. Before the detection standard of lowtemperature grouting material is issued, it is still of great significance to study the temperature-keeping measures

Copyright (C) 2020 Fangzhen Zhu et al.

doi:10.18282/ice.v3i1.314

This is an open-access article distributed under the terms of the Creative Commons Attribution Non-Commercial License (http://creativecommons. org/licenses/by-nc/4.0/), which permits unrestricted non-commercial use, distribution, and reproduction in any medium, provided the original work is properly cited. 
of ordinary normal-temperature grouting material during winter construction. Based on the statistics of temperature changes in November, December, January and February in Zhengzhou in the past three years (as shown in Figure 1), it is easy to see that the time period when the ambient temperature is lower than $5{ }^{\circ} \mathrm{C}$ is generally from the end of November to the end of February, except for last year's rest and rain.

In the snowy weather, the time for sleeve grouting in winter is generally more than one month, while in the southern region, it is shorter. Considering the economic angle, it is more economical and effective to adopt the thermal insulation measures for winter construction than to detect the use of low-temperature grouting materials.

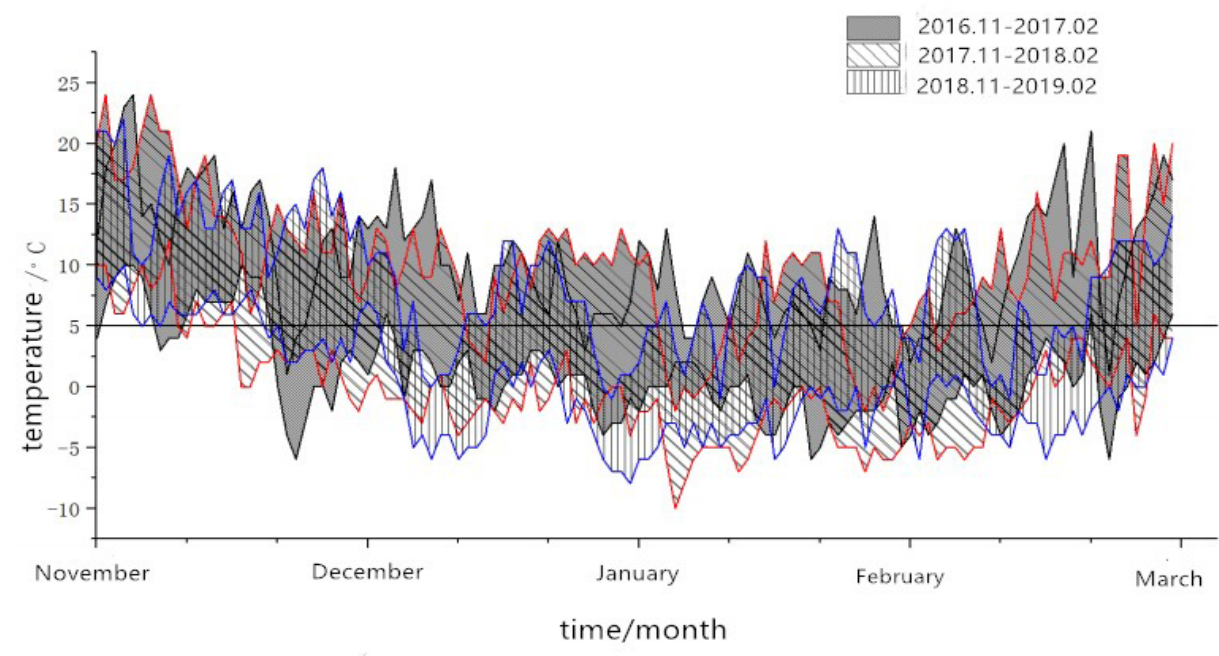

Fig.1 Variation Curve of maximum temperature and minimum temperature in Zhengzhou in recent three years

Figure 1. Variation Curve of maximum temperature and minimum temperature in Zhengzhou in recent three years.

\section{Test design}

\subsection{Test raw materials and equipment}

Main raw materials: the HRB400 steel bar with a diameter of $14 \mathrm{~mm}$ and grouting material adopt normal temperature grouting material produced by Wuhan yuanjin building materials science and technology co., ltd. Insulation materials: first, external application of electric blanket with power of 50W/m and XPS insulation board with thickness of $5 \mathrm{~cm}$; The second is that the winding power of the outer wall of the sleeve is $20 \mathrm{~W} / \mathrm{m}$ and the width is $8 \mathrm{~mm}$.

Main equipment: The temperature detection adopts THJ multi-channel touring detector as shown in Figure 2 and cement mortar bending and compression resistance test integrated machine.

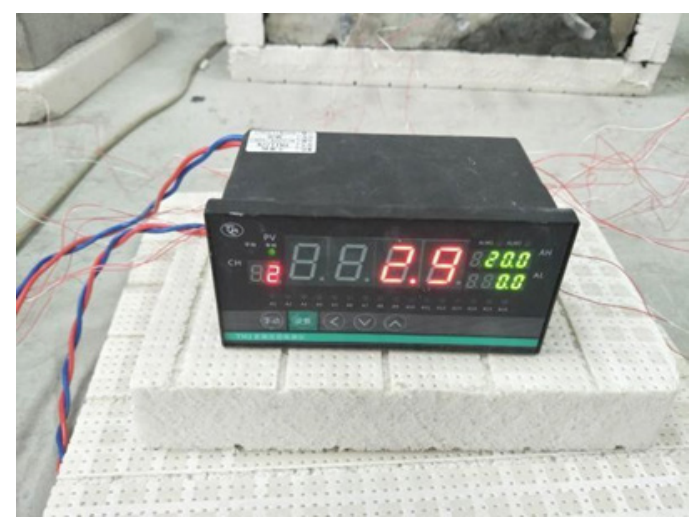

Figure 2. THJ multi-channel itinerant detector.

\subsection{Test plan}

Make $500 \mathrm{~mm} \times 200 \mathrm{~mm} \times 300 \mathrm{~mm}$ concrete wallboard, embed 6 grouting sleeve specimens of GTZB4 14B, insert the lower reinforcing bar at the lower opening of the sleeve according to the standard anchoring depth, then block the lower opening, and embed the whole into the concrete. A The test block only covers the electric blanket and the XPS insulation board on the outer surface. The B test block is covered with electric blanket and XPS insulation board on the 
outer surface and both sides. The C group test block is wrapped with an electric tracing tape on the outer wall of the sleeve. The D group test block is only covered with the XPS insulation board on the outer surface and both sides (as shown in Figure 3). The THJ multi-channel tour detector is used to monitor the temperature value of each measuring point in the recording chart.
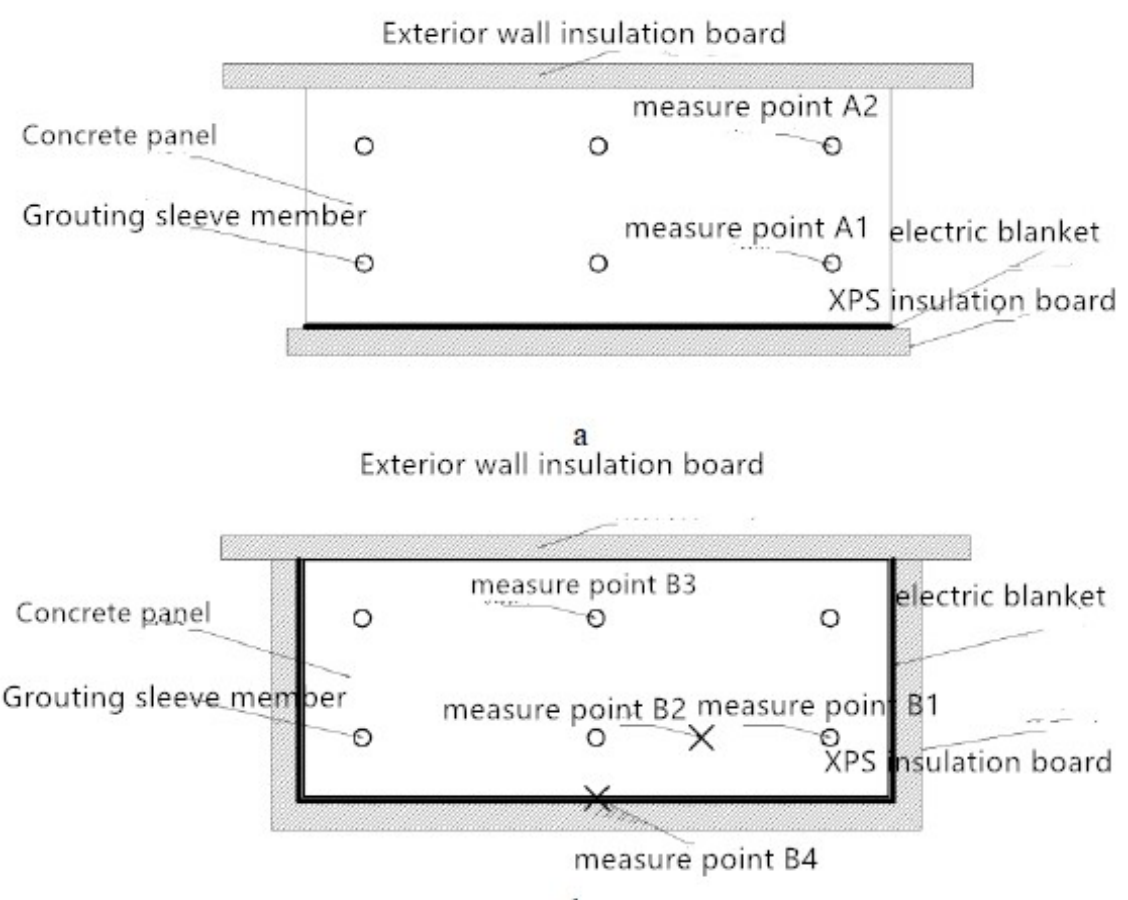

b
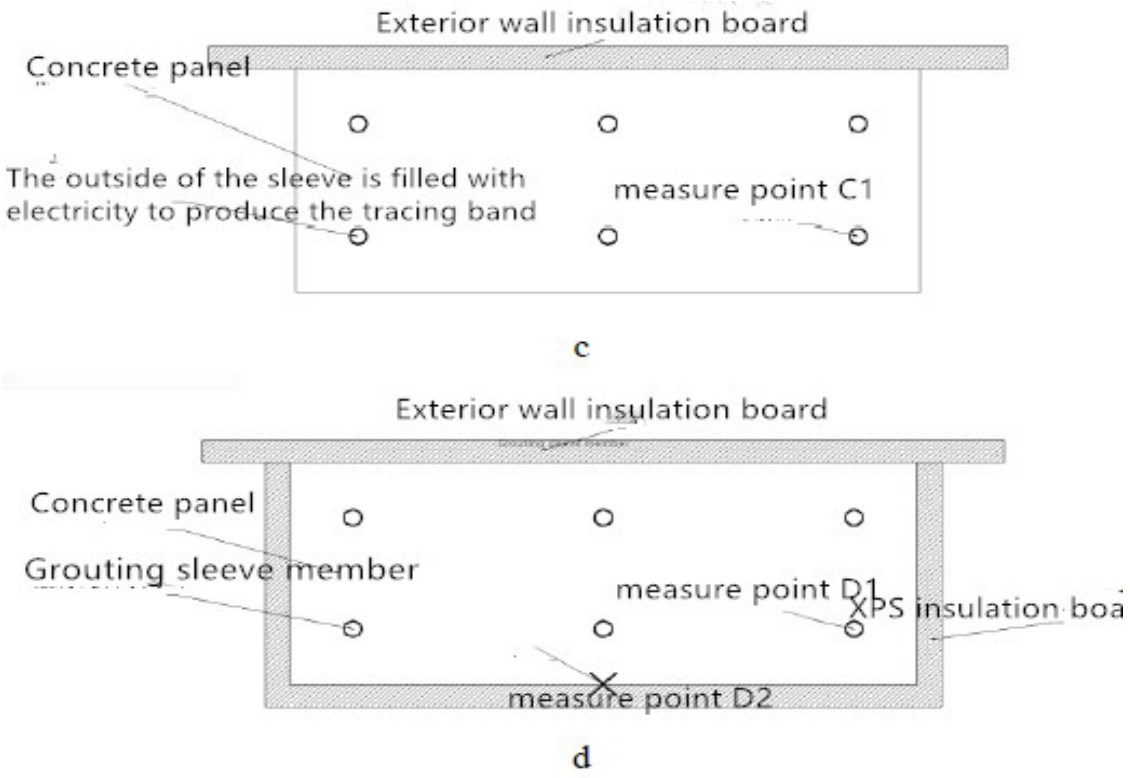

Figure 3. Schematic diagram of thermal insulation measures in each group.

\subsection{Test operation process}

The whole process of the experiment was carried out on the construction site of the high-end talent building project of Henan medical innovation and transformation base. The grouting time is set at 3 o'clock in the afternoon, and the sleeve grouting material and test equipment are placed at the test environment temperature 24 hours in advance during the test.

In the low temperature environment, the higher the mold entry temperature of the grout mixture, the higher its early strength; Prolonging the stirring time can appropriately increase the fluidity of the mixture ${ }^{[5]}$. Therefore, during the test, $50{ }^{\circ} \mathrm{C}$ warm water shall be used for weighing according to the water cement ratio required by the manufacturer. In order 
to prevent dust and splash, water shall be poured first and then grouting material shall be added. During the mixing, a hand-held mixer shall be used to uniformly stir for $5 \mathrm{~min}$. After the mixing is confirmed to be uniform, the mixture shall be allowed to stand for $2 \mathrm{~min}$, and the mixture shall not be used until all bubbles disappear. The measured initial fluidity $\geq 300 \mathrm{~mm}$ and " $30 \mathrm{~min}$ fluidity $\geq 260 \mathrm{~mm}$ meet the requirements ${ }^{[6]}$ of grouting material for steel bar connection (JG/T 408-2013). However, due to the low ambient temperature, the temperature of the mixture has dissipated to about $15 \mathrm{C}$ after mixing. At the same time, the sleeves in the concrete wallboard are preheated by a blower, each sleeve is preheated for $30 \mathrm{~s}$, and after preheating, the grouting port and the slurry outlet are blocked by plugs to prevent heat loss, and the sleeves are opened again when grouting is performed; In order to study the heating curve of the electric tracing band, the $\mathrm{C}$ group test block was not preheated. After preheating, the hand-held manual grouting gun shall be used for grouting rapidly. After grouting is completed, heat preservation measures for each group of test blocks shall be laid. The 12 road THJ multi-channel tour detector is used to monitor and record the temperature value of each measuring point every $10 \mathrm{~min}$, and the ambient temperature is the temperature value measured close to the concrete surface.

\section{Test and analysis}

After the heat preservation measures are set up, the patrol recorder records the temperature every $10 \mathrm{~min}$ and the temperature value of $24 \mathrm{~h}$. The mixed grouting material is retained in the 6 group of $40 \mathrm{~mm} \times 40 \mathrm{~mm} \times 160 \mathrm{~mm}$ test blocks, of which the 3 group is used for curing under the same environment, and the 3 group is cured in the building materials test curing room of Zhengzhou university's north campus (as shown in Figure 4), which are used for measuring the compressive strength and flexural strength for 1, 3 and 28 days respectively. Referring to GB/T 176711999 Testing Method for Strength of Cement Mortar (ISO Method) ${ }^{[8]}$,the test block is first subjected to bending test on a cement mortar bending and compression test integrated machine to break the test block into two halves, and then the compressive strength of the grouting material test block is measured at a loading rate of 2.4KN/s (as shown in Figure 4).

The compressive strength of grouting materials cured at low temperature in the same environment does not meet the specification requirements, and the early strength is greatly affected by the low temperature environment, reaching only about $50 \%$ of the specified strength in the specification; However, with the slow growth of its later strength, it reached $90 \%$ of the specified strength at $28 \mathrm{~d}$ ". However, the compressive strength of grouting material test blocks cured in the curing room all meet the specification requirements. This shows that the early strength of grouting material has great influence on its strength growth. Early strength cement can be used or heat preservation and curing measures can be taken to make the early strength reach the specification.

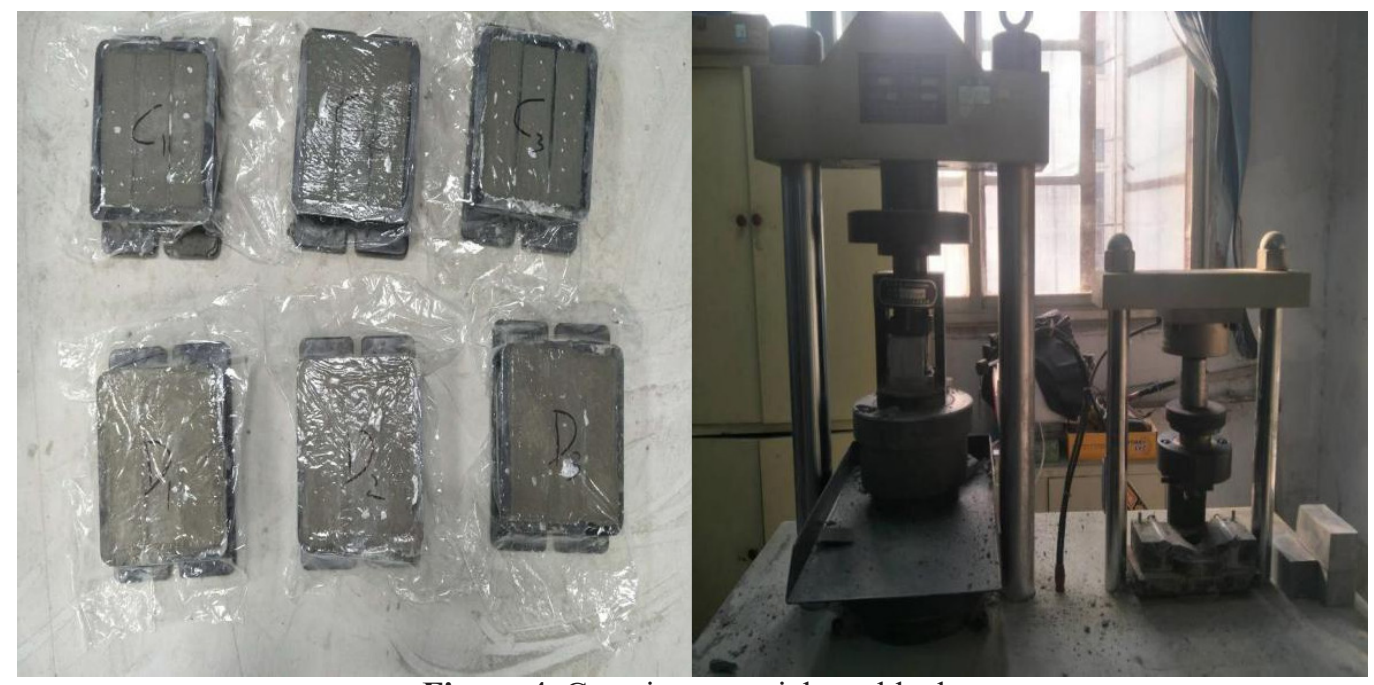

Figure 4. Grouting material test block.

\section{Engineering application}

The high-end talent building project of Henan medical innovation and transformation base is an apartment building community. The construction method is fabricated, with a total floor area of $75457.61 \mathrm{~m}^{2}$, a total floor area of $223075.16 \mathrm{~m}^{2}$, underground 3 floors and overground 18 floors, of which 5 17 floors are fabricated shear wall structures. 
The prefabricated components of the project include: prefabricated concrete outer wall, prefabricated concrete inner wall, prefabricated bottom plate, prefabricated stairs, prefabricated air conditioning plate and floating window plate, with a prefabrication rate of $26.95 \%$. Prefabricated wall adopts the domestic advanced reinforced sleeve grouting connection system.

From the late November of 2018 to February of 2019, the ambient temperature of grouting construction has been lower than $5^{\circ} \mathrm{C}$ for a long time. In order to ensure the connection quality and construction schedule, thermal insulation measures of electric blanket and XPS insulation board have been developed and adopted. The operation technology in grouting construction is as follows:

(1). Put the grouting material into the greenhouse $24 \mathrm{~h}$ in advance. During grouting, warm water of $40{ }^{\circ} \mathrm{C}$ to $60{ }^{\circ} \mathrm{C}$ shall be used for mixing, and the water temperature shall not exceed $65^{\circ} \mathrm{C}^{[9]}$. A movable greenhouse shall be set up in the construction area. Mixing of the grouting material shall be carried out in the greenhouse to prevent the temperature from losing too fast.

(2). The grouting construction shall be carried out in the morning when the temperature rises. When the grouting material is mixed, the mixing time shall be $5 \sim 6 \mathrm{~min}$. After the mixing is uniform, the grouting shall be allowed to stand for $2 \mathrm{~min}$, and the grouting shall be carried out after the bubbles completely disappear. In order to ensure the quality of grouting material, the initial fluidity and 30min fluidity are tested, and the grouting material test block is retained in a 10-20 temperature greenhouse for curing ${ }^{[10-11]}$ until the $28 \mathrm{~d}$ sample is sent for testing, and the $28 \mathrm{~d}$ compressive strength is greater than $85 \mathrm{MPa}$, which meets the specification requirements.

(3). Two HYDZ-PT100 temperature sensors with a specification of $2 \times 10 \times 1000 \mathrm{~mm}$ are embedded in each wall panel sleeve to detect the temperature change of grouting material in the sleeve.

(4). Preheat the sleeves with tungsten lamp or blower before grouting. Each sleeve shall be preheated for about $30 \mathrm{~s}$. After preheating, the grout outlet and grouting outlet shall be blocked in time. Grouting shall be carried out while preheating, and grouting shall be carried out in each section.

(5). Immediately after grouting is completed, the electric blanket and XPS insulation board shall be laid, and the board shall be tightly propped to make the electric blanket tightly cling to the wall surface. And the temperature value is recorded every $2 \mathrm{~h}$.

(6). Do not disturb grouting parts and insulation materials, and remove insulation measures after 24h. At present, the winter construction of sleeve grouting in this project has been successfully completed. Simulation test and temperature record of precast shear wall plate before grouting.

\section{Conclusion}

(1). The prefabricated shear wall board adopts the scheme of electric blanket plus XPS insulation board. The temperature of grouting material in the sleeve is above $10{ }^{\circ} \mathrm{C}$, and the maximum temperature can reach 20 . According to the compressive strength value of grouting material test block in the curing room, this kind of insulation measure is feasible, and no insulation can be set on both sides. However, the influence of wall thickness should be considered when using this method.

(2). The electric heating tape is wrapped around the sleeve wall. Even without preheating, the temperature can be raised to above $5^{\circ} \mathrm{C}$ in a very short time, and the maximum temperature for 24 hours is 25.9 . When this method is adopted, the electric tracing band with appropriate power should be selected according to the actual ambient temperature to prevent the grouting material from being invalid due to too high temperature. The method is simple and effective, can be matched with batch production of grouting sleeves, and can effectively solve winter construction of sleeve grouting.

(3). It is not feasible to cover XPS insulation board or quilt only on the outside of prefabricated shear wall board. Due to the concealment of the grouting connection of the steel sleeve, its connection performance is not easy to detect, so the insulation measures cannot be selected only based on the winter construction experience of general projects. Test blocks under the same conditions should be retained to detect the temperature change of grouting material in the sleeve for test verification.

(4). Under low temperature environment, the early strength of normal temperature grouting material increases slowly, but the later strength can reach $90 \%$ of the strength specified in the specification. Therefore, heat preservation 
measures should be taken to keep the average temperature above $10{ }^{\circ} \mathrm{C}$ in one day. Or adding aluminate or magnesium phosphate and other ultra-early strength cement into the cementing material to make its early strength meet the specification requirements, but at the same time, it is necessary to ensure the growth of the later strength.

(5). From an economic point of view, when the minimum temperature of the environment is above $-5^{\circ} \mathrm{C}$, it is more economical to adopt temperature-keeping measures in high-end talent building projects than to switch to lowtemperature grouting materials, and the quality inspection is standard and easy to control.

\section{References}

1. Ministry of Housing and Urban-Rural Development of the People's Republic of China, JGJ355-2015. Technical Specification for Application of Steel Sleeve Grouting Connection, S. Beijing: China Construction Industry Press, 2015.

2. Gu Haosheng, Wu Jiapeng. Influence of ambient temperature on performance of reinforced sleeve grouting joint [J]. Structural Engineer, 2017, 33 (5): 140-147.

3. Yang Guogang, Hou Weihong, Wu Wenxuan. Study on the Application Performance of Sleeve Grouting Material at Low Temperature [J]. Concrete and Cement Products, 2018,4 (4):90-94.

4. Zhu Qinghua, Liu Xingya, Qian Guanlong. Application of sleeve grouting material for low negative temperature steel bar connection [J]. Construction Technology, 2016,45 (10): 49-51.

5. Li Xiaoming, Su Zhongchun, Chen Tao. Effect of curing temperature on strength development of low-temperature grouting material [J]. China Harbour Construction, 2014,7 (7): 47-49.

6. Ministry of Housing and Urban-Rural Development of the People's Republic of China, JG/T408-2013. Sleeve grouting material for steel bar connection [S]. Beijing: China Construction Industry Publishing House, 2013.

7. Ma Cong, Zhu Wanxu, Ma Qian. Grouting Technology of Grouting Sleeve in Construction Site [J]. Concrete, 2013,9 (9): $153-155$.

8. Ministry of Housing and Urban-Rural Development of the People's Republic of China, GB/T17671-1999. Testing Method for Strength of Cement Mortar (ISO Method ) S. Beijing: China Construction Industry Press,

9. Ministry of Housing and Urban-Rural Development of the People's Republic of China, GB50119-2013. Technical Specification for Application of Concrete Admixtures, S. Beijing: Chinese Architecture.Industrial Publishing House, 2013.

10. Zhang Haibo, Chen Hang, Zhu Qinghua. Feasibility Study on Grouting Connection of Fabricated Structure Reinforced Sleeve at Low Temperature [J]. Construction Technology, 2017.46 (4): 18-20.

11. Li Shiyuan ;Research on Prefabricated Building Steel Sleeve Grouting Material ;D ;Beijing: Beijing Municipal Engineering Research Institute; 2017. 